\title{
HUBUNGAN ANTARA DUKUNGAN KELUARGA DENGAN KEAKTIFAN PESERTA POSYANDU LANSIA MENGIKUTI POSYANDU LANSIA DESA SUDIMARA DAN DESA GUBUG KABUPATEN TABANAN 2019
}

\author{
Nur Saadah*, Dinar Saurmauli Lubis, Desak Yuli Kurniati \\ Alamat: Program Studi Kesehatan Masyarakat Fakultas Kedokteran Universitas Udayana \\ *email: sasaapel26@gmail.com
}

\begin{abstract}
ABSTRAK
Meningkatkan derajat kesehatan lansia merupakan hal penting yang harus dilakukan oleh pemerintah. Salah satu upaya dalam meningkatkan derajat kesehatan lansia adalah posyandu lansia. Perilaku peserta posyandu lansia berkunjung ke tempat pelayanan kesehatan ditentukan oleh tiga faktor. Di antara ketiga faktor tersebut, faktor dukungan keluarga sangat penting karena sebagai faktor penguat dari perilaku seseorang. Oleh karena itu, penelitian ini bertujuan untuk mengetahui hubungan antara dukungan keluarga dengan keaktifan peserta posyandu lansia mengikuti posyandu lansia di desa Sudimara dan Gubug kabupaten Tabanan 2019. Variabel dependent penelitian ini adalah dukungan keluarga yang terdiri dari sub variable dukungan emosional, dukungan penghargaan, dukungan instrumental, dukungan informasional. Variabel independen penelitian ini adalah keaktifan peserta posyandu lansia. Desain penelitian ini menggunakan crossectional. Populasi adalah seluruh lansia yang tercatat di 2 desa yaitu Desa Sudimara dan Desa Gubug berjumlah 113 lansia. Data dianalisis dengan uji chi square dan diolah dengan menggunakan software komputer. Responden mendapat dukungan baik dari keluarganya secara emosional dan penghargaan, instrumental, dan juga dukungan informasional. Responden dalam penelitian ini aktif mengikuti kegiatan posyandu lansia yaitu sebanyak 73 responden $(64,6 \%)$. Hubungan dukungan keluarga secara umum tidak berpengaruh secara statistik dengan keaktifan peserta posyandu lansia ( $\mathrm{p}=0,319 ; 95 \% \mathrm{CI}$ OR=0,683-3,215; OR=1,48).
\end{abstract}

Kata Kunci: Dukungan Keluarga, Emosional, Instrumental, Informasional, Lansia.

\begin{abstract}
Improving the health status of the elderly is an important thing that must be done by the government. One effort to improve the health status of the elderly is posyandu for the elderly. The behavior of the elderly posyandu participants visiting health services is determined by three factors. Among the three factors, the factor of family support is very important because it is a reinforcing factor of a person's behavior. Therefore, this study aims to determine the relationship between family support and the active participation of elderly posyandu participants in the elderly posyandu in Sudimara and Gubug Tabanan regency 2019. The dependent variable of this study was family support consisting of sub-variables emotional support, award support, instrumental support , informational support. The independent variable of this research is the activity of the elderly posyandu participants. The design of this study uses cross-sectional. The population is all the elderly recorded in 2 villages, namely Sudimara Village and Gubug Village totaling 113 elderly. Data were analyzed by chi square test and processed using computer software. Respondents received good support from their families emotionally and appreciation, instrumental, and also informational support. Respondents in this study actively participated in the elderly posyandu activities as many as 73 respondents (64.6\%). The relationship of family support in general did not have a statistical effect on the activity of elderly posyandu participants $(\mathrm{p}=0.319 ; 95 \% \mathrm{CI}$ OR $=0.683-3.215$; $\mathrm{OR}=1.48$ ).
\end{abstract}

Keywords: Family Support, Emotional, Instrumental, Informational, Elderly.

\section{PENDAHULUAN}

Pembangunan kesehatan adalah salah satu upaya pembangunan nasional yang bertujuan meningkatkan kesadaran, kemauan, dan kemampuan untuk hidup sehat bagi setiap orang agar terwujud derajat kesehatan masyarakat yang setinggi-tingginya. Pembangunan kesehatan di Indonesia saat ini dihadapkan pada beban ganda, di satu pihak penyakit menular belum terselesaikan dan di lain pihak telah 
terjadi peningkatan penyakit tidak menular (PTM). PTM merupakan penyakit yang lebih banyak disebabkan oleh gaya hidup manusia atau sering dikenal juga dengan penyakit degeneratif. (Kemenkes RI, 2012)

PTM sebagian besar di dialami oleh pra lansia, lansia atau lansia resiko tinggi. Beberapa wilayah di Indonesia akan mengalami ledakan penduduk lansia (lanjut usia) pada tahun 2010 hingga 2020. Jumlah lansia diperkirakan akan naik mencapai $11,34 \%$ dari jumlah penduduk Indonesia. Berdasarkan data Badan Pusat Statistik (BPS) pada tahun 2014, jumlah lansia di Indonesia mencapai 20,24 juta jiwa, setara dengan 8,03 persen dari seluruh penduduk Indonesia tahun 2014. Jumlah lansia perempuan lebih besar daripada laki-laki, yaitu 10,77 juta lansia perempuan dibandingkan 9,47 juta lansia laki-laki. Jumlah tersebut diantaranya berada di Provinsi Yogyakarta (13,05 persen), Jawa Tengah (11,11 persen), Jawa Timur (10,96 persen), dan Bali (10,05 persen).

Berdasarkan Data Lansia Kabupaten Tabanan 2018, total usia lanjut Kabupaten Tabanan adalah 88289 jiwa dengan jumlah laki-laki 44410 jiwa dan perempuan 43879 jiwa, serta usia lanjut resiko tinggi 25863 jiwa dengan jumlah laki-laki 11744 jiwa dan perempuan 14119 jiwa, sedangkan di Desa Sudimara dan Desa Gubug Kecamatan Tabanan pada 2018 adalah total usia lanjut 2338 dengan jumlah laki-laki 1119 jiwa dan perempuan 1219 jiwa, serta usia lanjut resiko tinggi yaitu 1182 dengan jumlah laki-laki 564 jiwa dan perempuan 618 jiwa. Total keseluruhan lansia di Desa Sudimara dan Desa Gubug Kecamatan Tabanan adalah 3520 jiwa (Dinas Kesehatan Kabupaten Tabanan, 2018).

Peningkatan lansia setiap tahun menunjukan perlu adanya suatu upaya untuk menjaga kesehatanya. Salah satu upaya yang dilakukan pemerintah adalah dengan membentuk posyandu lansia, Posyandu lansia adalah suatu forum komunikasi, alih teknologi dan pelayanan kesehatan oleh masyarakat dan untuk masyarakat yang mempunyai nilai strategis untuk pengembangan sumber daya manusia khususnya lanjut usia (Depkes, 2000). Posyandu lansia merupakan salah satu program pemberdayaan masyarakat yang di bentuk oleh pemerintah melalui puskesmas. Salah satu puskesmas yang menjalankan Posyandu lansia adalah Puskesmas Tabanan I. Puskesmas Tabanan I Mewilayahi 4 Desa Yaitu, Desa Dauh Peken, Desa Bongan, Desa Gubug dan Desa Sudimara. Akan tetapi, Posyandu Lansia di Desa Sudimara dan Gubug tingkat kehadirannya masih rendah.

Berdasarkan studi pendahuluan di posyandu lansia Desa Sudimara dan Desa Gubug didapatkan bahwa jumlah kunjungan peserta posyandu cenderung menurun. Hal ini terlihat dari jumlah kunjungan posyandu di Desa Sudimara dan Desa Gubug selama 2018 berdasarkan usia di atas 60 keatas, bulan September 2018 tercatat di pemegang program sebanyak 125 orang yang terdaftar di Posyandu Lansia, tetapi tingkat kehadiran bulan Oktober sebanyak 84 orang $(67,2 \%)$, di bulan November sebanyak 97 orang 
(77,6\%) dan pada bulan Desember 81 orang $(64,8 \%)$ yang hadir mengikuti posyandu Lansia. Kehadiran dikatakan aktif $\geq 80 \%$ dan dinyatakan kurang aktif $<$ $80 \%$. Dari data diatas menunjukkan bahwa frekuensi kehadiran pada bulan September, Oktober, November, dan Desember 2018 belum mencapai target.

Perilaku peserta posyandu lansia berkunjung ke tempat pelayanan kesehatan ditentukan oleh tiga faktor. Pertama, faktor predisposisi antara lain pengetahuan, sikap, kepercayaan, nilai, dan karakteristik individu. Kedua, faktor pemungkin antara lain ketersediaan sarana kesehatan, jarak tempuh, hukum pemerintah, keterampilan terkait kesehatan. Ketiga, faktor penguat antara lain keluarga, teman sebaya, guru, tokoh masyarakat (Handayani, 2012 dalam Umayana \& Cahyati 2015). Menurut Trihardini (2007), salah satu komponen dalam terbentuknya keinginan seseorang mengikuti pelayanan kesehatan adalah situasi sosial seperti keluarga, teman dekat, teman kerja dan lingkungan. Di antara ketiga faktor tersebut, faktor dukungan keluarga sangat penting karena sebagai faktor penguat dari perilaku seseorang.

\section{METODE PENELITIAN}

Penelitian ini merupakan penelitian deskriptif dengan pendekatan cross sectional yaitu suatu metode penelitian yang dilakukan dengan tujuan untuk membuat gambaran tentang suatu keadaan secara obyektif tentang hubungan antara dua variabel pada sekelompok subyek. Penelitian ini dilakukan untuk melihat hubungan antara variabel satu dengan yang lainnya dan dikumpulkan secara simultan atau dalam waktu yang bersamaan. Penelitian dilakukan Bulan April. Sampel dalam penelitian ini adalah seluruh populasi atau total populasi yang tercatat dalam Posyandu Lansia Desa Sudimara dan Desa Gubug yang berjumlah 125 orang. Pengambilan sampel dalam penelitian ini menggunakan teknik non probability sampling yang di hitung berdasarkan rumus perhitungan sampel Notoatmojo (2003) Pengambilan sampel penelitian ini sesuai dengan kriteria inklusi dan eksklusi.

Data yang digunakan dalam penelitian ini adalah data primer yang di peroleh dari hasil pengisian alat pengumpulan data. Alat yang digunakan untuk mengumpulkan data pada penelitian ini adalah lembar kuesioner yang berisikan pernyataan-pernyataan mengenai dukungan keluarga dan keaktifan peserta posyandu lansia. Bagian pertama yaitu kuesioner yang digunakan untuk menilai dukungan keluarga yang dikembangkan oleh Nursalam 2014, yang dimodifikasi oleh dengan jumlah 12 pernyataan yang skornya 3 untuk jawaban selalu, skor 2 untuk jawaban kadangkadang, dan skor 1 untuk jawaban tidak pernah. Nilai tertinggi yaitu 3 dan nilai terendah yaitu 1 dengan skor maksimal yaitu 36 dan skor minimal yaitu 12 .

Bagian kedua yaitu kuesioner yang digunakan untuk menilai keaktifan peserta posyandu lansia dengan jumlah 11 pernyataan yang skornya 3 untuk jawaban selalu, skor 2 untuk jawaban kadang- 
kadang, dan skor 1 untuk jawaban tidak pernah. Nilai tertinggi yaitu 3 dan nilai terendah yaitu 1 dengan skor maksimal yaitu 33 dan skor minimal yaitu 11 .

Pengumpulan data dilakukan di posyandu lansia Desa Sudimara dan Desa Gubug dengan memberikan kuesioner kepada responden untuk diisi dengan salah satu jawaban yang telah disediakan. Apabila responden mengalami kesulitan dalam pengisian kuesioner, maka responden di bantu oleh asisten peneliti.

Dilakukan analisis univariat dan analisis bivariat. Analisis univariat dalam penelitian ini dilakukan untuk mengetahui karakteristik responden (umur, jenis kelamin, pendidikan, dan pekerjaan), distribusi dukungan keluarga, dan keaktifan peserta posyandu lansia. Data yang diperoleh dari hasil pengumpulan disajikan dalam bentuk tabel distribusi berupa nilai minimum, maksimum, mean dan standar devisiasi. Dilakukan Analisa bivariat pada tahap ini untuk meneteliti hubungan antara dua variabel yang meliputi variabel bebas dan terikat. Untuk membuktikan adanya hubungan antara dukungan keluarga dengan keaktifan peserta posyandu lansia di Desa Sudimara dan Desa Gubug Kecamatan Tabanan.

Uji statistik yang digunakan dalam penelitian ini adalah uji non-parametic test yaitu chi square dengan nilai $p<0,05$. Dukungan keluarga berhubungan dengan keaktifan peserta posyandu lansia apabila nilai p chi square lebih kecil dari 0,05.

\section{HASIL}

Hasil penelitian ini dilakukan di Desa Sudimara dan Desa Gubug dengan menggunakan data primer berupa kuisioner dukungan keluarga dan keaktifan. Pengumpulan data dilaksanakan pada bulan April 2019 dengan jumlah sasaran 125 orang, tetapi sebanyak 8 responden tidak bersedia untuk diwawancarai dan 4 responden lainnya tidak tinggal bersama keluarga. Jadi, responden yang memenuhi kreteria inklusi dan eklusi dalam penelitian ini sebanyak 113 responden.

Dari hasil analisis data diuraikan karakteristik responden berdasarkan umur, jenis kelamin, pendidikan dan pekerjaan yang akan disajikan dalam bentuk tabel 1. Pada tabel 1 dibawah dapat dilihat bahwa rata-rata umur responden pada penelitian ini adalah 68 tahun dengan standar deviasi 6,01. Sebagian besar responden dalam penelitian ini berumur diatas 65 tahun sebanyak 78 responden $(69,0 \%)$. untuk jenis kelamin yang terbanyak yaitu lakilaki sebanyak 66 responden (58,4\%). Pekerjaan yang paling banyak adalah dengan kategori lain-lain seperti,nelayan, IRT, Pensiunan dan tidak bekerja sebanyak 44 responden (38,9\%). sedangkan pendidikan yang paling banyak ditempuh adalah SMA sebanyak 47 responden $(41,9 \%)$. 
Tabel 1. Distribusi Frekuensi Karakteristik Responden di Desa Sudimara dan Desa Gubug Tahun 2019 (n=113)

\begin{tabular}{ccc}
\hline Karakteristik & Frekuensi & Persentase (\%) \\
\hline Umur* (mean;SD) & 68,$79 ; 6,01$ & 31,0 \\
55-65 Tahun & 35 & 69,0 \\
>65 Tahun & 78 & \\
Jenis Kelamin & & 58,4 \\
Laki-laki & 66 & 41,6 \\
Perempuan & 47 & \\
Pekerjaan & & 25,7 \\
Petani & 29 & 31,0 \\
Kary. Swasta & 35 & 4,4 \\
Wirawasta & 5 & 38,9 \\
Lain-lain & 44 & \\
Pendidikan Terakhir & & 22,1 \\
Tidak Sekolah & 25 & 24,8 \\
SD & 28 & 4,4 \\
SMP & 5 & 41,6 \\
SMA & 47 & 7,1 \\
Perguruan Tinggi & 8 & \\
\end{tabular}

Dukungan yang diberikan keluarga pada lansia dalam merawat dan meningkatkan status kesehatan adalah memberikan pelayanan dengan sikap menerima kondisinya. Pada penelitian ini dukungan keluarga dilihat dari 3 aspek yaitu dukungan emosional dan penghargaan, dukungan instrumental, dan dukungan informasional. Distribusi frekuensi masing-masing item dukungan keluarga di sajikan pada tabel berikut ini.

Tabel 2. Distribusi frekuensi item dukungan Keluarga terhadap peserta posyandu Lansia $(\mathrm{n}=113)$

\begin{tabular}{lccc}
\hline \multicolumn{1}{c}{ Dukungan Keluarga } & $\begin{array}{c}\text { Tidak } \\
\text { pernah }\end{array}$ & $\begin{array}{c}\text { Kadang- } \\
\text { kadang }\end{array}$ & Selalu \\
\cline { 3 - 4 } & $\mathbf{n} \mathbf{( \% )}$ & $\mathbf{n}(\mathbf{\%})$ & $\mathbf{n}(\mathbf{\%})$ \\
\hline $\begin{array}{l}\text { Dukungan Emosional dan Penghargaan } \\
\text {-Keluarga mendampingi saya saat kegiatan Posyandu } \\
\text { Lansia }\end{array}$ & $10(8,8)$ & $34(30,1)$ & $69(61,1)$ \\
$\begin{array}{l}\text {-Keluarga memberi pujian dan perhatian kepada saya } \\
\text { setiap mengikuti kegiatan Posyandu Lansia }\end{array}$ & $0(0,0)$ & $27(23,9)$ & $86(76,1)$ \\
$\begin{array}{l}\text {-Keluarga tetap mencintai dan memperhatikan } \\
\text { keadaan saya }\end{array}$ & $0(0,0)$ & $14(12,4)$ & $99(87,6)$ \\
$\begin{array}{l}\text { Dukungan Instrumental } \\
\text {-Keluarga menyediakan waktu dan kendaraan untuk }\end{array}$ & $2(1,8)$ & $30(26,5)$ & $81(71,7)$ \\
\hline
\end{tabular}




\begin{tabular}{|c|c|c|c|}
\hline mengantar saya ke Posyandu Lansia & & & \\
\hline $\begin{array}{l}\text {-Keluarga sangat berperan aktif dalam setiap kegiatan } \\
\text { Posyandu Lansia }\end{array}$ & $0(0,0)$ & $22(19,5)$ & $91(80,5)$ \\
\hline $\begin{array}{l}\text {-Keluarga bersedia membiayai keperluan saya untuk } \\
\text { mengikuti Posyandu Lansia }\end{array}$ & $0(0,0)$ & $14(12,4)$ & $99(87,6)$ \\
\hline Dukungan Informasional & & & \\
\hline $\begin{array}{l}\text {-Keluarga memberitahu tentang manfaat Posyandu } \\
\text { Lansia }\end{array}$ & $0(0,0)$ & $32(28,3)$ & $81(71,7)$ \\
\hline $\begin{array}{l}\text {-Keluarga mengingatkan kepada saya jadwal kegiatan } \\
\text { Posyandu Lansia }\end{array}$ & $1(0,9)$ & $30(26,5)$ & $82(72,6)$ \\
\hline $\begin{array}{l}\text {-Keluarga mengingatkan kepada saya tentang } \\
\text { perilaku-perilaku yang dapat memperburuk } \\
\text { kesehatan saya }\end{array}$ & $2(1,8)$ & $14(12,4)$ & $97(85,8)$ \\
\hline $\begin{array}{l}\text {-Keluarga mengingatkan saya setiap saya bertanya } \\
\text { hal-hal yang tidak jelas tentang Posyandu Lansia }\end{array}$ & $2(1,8)$ & $9(8,0)$ & $102(90,3)$ \\
\hline
\end{tabular}

Pada tabel 2 menunjukan bahwa 69 responden $(61,1 \%)$ secara umum keluarga selalu mendampingi dalam kegiatan posyandu lansia sementara terdapat 10 responden $(8,8 \%)$ keluarga tidak pernah mendampingi dalam kegiatan posyandu lansia dan 69 responden $(61,1 \%)$ keluarga selalu memberikan pujian dan perhatian setiap mengikuti kegiatan posyandu lansia sementara tidak ada keluarga responden $(0,0 \%)$ yang tidak pernah memberikan pujian dan perhatian setiap mengikuti kegiatan posyandu lansia. Sebanyak 99 responden $(87,6 \%)$ merasa keluarganya selalu mencintai dan memperhatikan keadaanya dan 101 responden $\quad(89,4 \%) \quad$ keluarganya memaklumi bahwa semakin usia lanjut akan rentan menderita berbagai penyakit.

Pada dukungan keluarga sebagai instrumental terdapat 81 responden $(71,7 \%)$ memiliki Keluarga yang selalu menyediakan waktu dan kendaraan untuk mengantar ke posyandu lansia sementara terdapat 2 responden (1,8\%) memiliki Keluarga yang tidak pernah menyediakan waktu dan kendaraan untuk mengantar ke posyandu lansia. Terdapat 91 responden (80,5\%) keluarga yang selalu berperan aktif dalam setiap kegiatan posyandu lansia yang diikuti sementara tidak terdapat responden $(0,0 \%)$ yang keluarganya berperan aktif dalam setiap kegiatan posyandu lansia yang diikuti. Terdapat 99 responden $(87,6 \%)$ keluarga yang selalu bersedia membiayai keperluan untuk mengikuti posyandu lansia dan terdapat 91 responden $(80,5 \%)$ keluarga yang selalu berusaha untuk mencari kekurangan sarana dan peralatan yang saya butuhkan dalam mengikuti posyandu lansia.

Pada dukungan keluarga sebagai informasional terdapat 81 responden (71,7\%) memiliki Keluarga yang selalu memberitahu tentang manfaat posyandu lansia dan terdapat 82 responden $(72,6 \%)$ keluarga yang selalu mengingatkan kepada peserta posyandu tentang jadwal kegiatan posyandu lansia yang diikuti. Terdapat 97 responden $(85,8 \%)$ keluarga yang selalu mengingatkan kepada peserta 
posyandu tentang perilaku-perilaku yang dapat memperburuk kesehatan responden dan terdapat 102 responden (90,3\%) keluarga yang selalu mengingatkan kepada peserta posyandu setiap bertanya hal-hal yang tidak jelas tentang Posyandu lansia.

Setiap aspek dukungan keluarga dikategorikan menjadi baik atau kurang.
Dukungan keluarga di kategorikan baik apabila total skor responden lebih besar dari atau sama dengan nilai median, sedangkan dukungan keluarga di kategorikan kurang apabila total skor responden lebih kecil dari median. Berikut ini gambaran distribusi dukungan keluarga responden penelitian.

Tabel 3. Distribusi frekuensi dukungan keluarga peserta posyandu lansia

\begin{tabular}{lll}
\hline \multicolumn{1}{c}{ Dukungan } & Frekuensi & Persentase \\
\hline Dukungan keluarga (mean) & 33,40 & \\
Baik & 58 & 51.3 \\
Kurang & 55 & 48.7 \\
\hline
\end{tabular}

Tabel 3 menunjukan bahwa dan penghargaan, instrumental, dan juga sebagian responden mendapat dukungan dukungan informasional. Terdapat 58 baik dari keluarganya secara emosional responden $(51,3 \%)$ yang mendapat dukungan keluarga baik.

Tabel 4. Distribusi frekuensi dukungan keluarga perkategori peserta posyandu lansia

\begin{tabular}{lll}
\hline \multicolumn{1}{c}{ Dukungan } & Frekuensi & Persentase \\
\hline $\begin{array}{l}\text { Dukungan Emosional dan Penghargaan } \\
\text { (mean) }\end{array}$ & 11,05 & \\
$\quad$ Baik & 66 & 58.4 \\
$\quad$ Kurang & 47 & 41.6 \\
Dukungan Instrumental (mean) & 11,19 & \\
$\quad$ Baik & 73 & 64.6 \\
$\quad$ Kurang & 40 & 35.4 \\
Dukungan informasional (mean) & 11,16 & \\
$\quad$ Baik & 73 & 64.6 \\
$\quad$ Kurang & 40 & 35.4 \\
\hline
\end{tabular}

Table 4 menunjukan bahwa pada aspek dukungan emosional dan penghargaan 66 responden $(58,4 \%)$ mendapat dukungan baik, 73 responden $(64,6 \%)$ mendapat dukungan baik dari aspek instrumental dan dukungan informasional yang di dapat responden sebagian besar tergolong baik sebanyak 73 responden $(64,6 \%)$.

Keaktifan peserta posyandu lansia dapat diasumsikan bahwa peserta yang aktif mengikuti setiap kegiatan yang 
dilaksanakan oleh Posyandu Lansia.

Berikut ini gambaran distribusi keaktifan

peserta posyandu lansia.

Tabel 5. Distribusi frekuensi setiap item keaktifan peserta posyandu lansia dalam mengikuti posyandu lansia $(n=113)$

\begin{tabular}{|c|c|c|c|}
\hline \multirow[t]{2}{*}{ Keaktifan Peserta Posyandu lansia } & $\begin{array}{c}\text { Tidak } \\
\text { pernah }\end{array}$ & $\begin{array}{l}\text { Kadang- } \\
\text { kadang }\end{array}$ & Selalu \\
\hline & n (\%) & n (\%) & n (\%) \\
\hline -Saya hadir saat kegiatan Posyandu Lansia & $0(0,0)$ & $58(51,3)$ & $55(48,7)$ \\
\hline -Saya mengikuti kegiatan senam di Posyandu Lansia & $0(0,0)$ & $50(44,2)$ & $63(55,8)$ \\
\hline $\begin{array}{l}\text {-Saya mengikuti penyuluhan yang diadakan di } \\
\text { Posyandu Lansia }\end{array}$ & $0(0,0)$ & $64(56,6)$ & $49(43,4)$ \\
\hline $\begin{array}{l}\text {-Saya mengikuti kegiatan jalan santai di Posyandu } \\
\text { Lansia }\end{array}$ & $0(0,0)$ & $55(48,7)$ & $58(51,3)$ \\
\hline $\begin{array}{l}\text {-Saya mengikuti kegiatan pengukuran tinggi badan di } \\
\text { Posyandu Lansia }\end{array}$ & $0(0,0)$ & $46(40,7)$ & $67(59,3)$ \\
\hline $\begin{array}{l}\text {-Saya mengikuti kegiatan pengukuran lingkar perut di } \\
\text { Posyandu Lansia }\end{array}$ & $0(0,0)$ & $40(35,4)$ & $73(64,6)$ \\
\hline $\begin{array}{l}\text {-Saya mengikuti kegiatan pengukuran IMT di Posyandu } \\
\text { Lansia }\end{array}$ & $0(0,0)$ & $40(35,4)$ & $73(64,6)$ \\
\hline $\begin{array}{l}\text {-Saya mengikuti kegiatan pengukuran tekanan darah di } \\
\text { Posyandu Lansia }\end{array}$ & $0(0,0)$ & $40(35,4)$ & $73(64,6)$ \\
\hline $\begin{array}{l}\text {-Saya mengikuti kegiatan pengecekan gula darah di } \\
\text { Posyandu Lansia }\end{array}$ & $0(0,0)$ & $40(35,4)$ & $73(64,6)$ \\
\hline $\begin{array}{l}\text {-Saya mengikuti kegiatan Posyandu Lansia dari awal } \\
\text { sampai akhir }\end{array}$ & $0(0,0)$ & $54(47,8)$ & $59(52,2)$ \\
\hline $\begin{array}{l}\text { - Dalam satu bulan terakhir, berapa kali anda hadir } \\
\text { dalam kegiatan posyandu lansia }\end{array}$ & $0(0,0)$ & $2(1,8)$ & $111(98,2$ \\
\hline
\end{tabular}

Pada tabel 5 menunjukan bahwa 55 responden $(48,7 \%)$ secara umum selalu hadir saat kegiatan posyandu lansia dan terdapat 63 responden $(55,8 \%)$ yang sering mengikuti kegiatan senam di posyandu lansia. Terdapat 49 responden (43,4\%) mengikuti penyuluhan yang diadakan di

Posyandu Lansia dan 58 responden (51,2\%) yang selalu mengikuti kegiatan jalan santai di posyandu lansia. Terdapat 67 responden (59,3\%) yang selalu mengikuti kegiatan pengukuran tinggi badan di posyandu lansia. Terdapat 73 responden $(64,6 \%)$ yang selalu mengikuti kegiatan pengukuran lingkar perut, pengukuran imt, pengukuran tekanan darah, dan pengecekan gula darah di posyandu lansia. Dalam satu bulan terakhir terdapat 111 responden $(98,2 \%)$ yang menyatakan selalu hadir dalam kegiatan posyandu lansia.

Keaktifan peserta posyandu lansia dikategorikan menjadi aktif atau tidak aktif. Keaktifan peserta posyandu di 
kategorikan aktif apabila total skor responden lebih besar dari atau sama dengan $80 \%$, sedangkan keaktifan peserta posyandu lansia di kategorikan tidak aktif apabila total skor responden lebih kecil dari $80 \%$. Berikut ini gambaran distribusi keaktifan peserta posyandu lansia.

Tabel 6. Distribusi frekuensi keaktifan peserta posyandu lansia

\begin{tabular}{lll}
\hline \multicolumn{1}{c}{ Keaktifan peserta posyandu lansia } & Frekuensi & Persentase \\
\hline Aktif & 73 & 64.6 \\
Tidak aktif & 40 & 35.4 \\
\hline
\end{tabular}

Tabel 6 menunjukan bahwa sebagian besar responden dalam penelitian ini Aktif mengikuti kegiatan posyandu lansia yaitu sebanyak 73 responden $(64,6 \%)$.
Hasil penelitian tentang variable dukungan keluarga, variable keaktifan peserta posyandu lansia mengikuti posyandu lansia disajikan pada tabel dibawah ini.

Tabel 7. Hubungan dukungan keluarga dengan keaktifan peserta posyandu lansia menggunakan uji chi square

\begin{tabular}{lcccc}
\hline & \multicolumn{2}{c}{ Keaktifan peserta posyandu lansia } & & \\
\cline { 2 - 3 } & $\begin{array}{c}\text { Aktif } \\
\mathrm{f}(\%)\end{array}$ & $\begin{array}{c}\text { Tidak aktif } \\
\mathrm{f}(\%)\end{array}$ & $\mathrm{P}$ & $\begin{array}{c}\text { OR } \\
(95 \% \text { CI OR })\end{array}$ \\
\hline $\begin{array}{l}\text { Dukungan keluarga } \\
\text { Baik }\end{array}$ & $40(69,0)$ & $18(31,0)$ & & 0,319 \\
$\quad$ Kurang & $33(60,0)$ & $22(40,0)$ & & $(0,683-3,215)$ \\
\hline
\end{tabular}

Tabel 7 menunjukkan bahwa dari responden yang medapat dukungan keluarga baik. 69\% nya aktif dalam kegiatan posyandu lansia, sedangkan dari responden yang dukungan keluarganya kurang hanya $60 \%$ yang aktif. Namun, hubungan dukungan keluarga tidak berpengaruh secara statistik dengan keaktifan peserta posyandu lansia, dengan nilai $\mathrm{p}>0,05(\mathrm{p}=0,319)$ dan nilai $95 \% \mathrm{CI}$
OR mencakup angka 1 (95\%CI OR= 0,6833,215). Namun demikian nilai OR hubungan dukungan keluarga dengan keaktifan peserta posyandu lansia adalah 1,48 , artinya odd peserta posyandu lansia yang mendapatkan dukungan baik dari keluarganya 1,48 kali lebih aktif dalam mengikuti kegiatan posyandu lansia dibandingkan dengan yang dukungan keluarganya kurang. 
Tabel 8. Hubungan dukungan keluarga per dimensi dengan keaktifan peserta posyandu lansia menggunakan uji chi square

\begin{tabular}{|c|c|c|c|c|}
\hline & \multicolumn{2}{|c|}{ Keaktifan peserta posyandu lansia } & \multirow[b]{2}{*}{$\mathrm{p}$} & \multirow[b]{2}{*}{$\begin{array}{c}\text { OR } \\
(95 \% \text { CI OR) }\end{array}$} \\
\hline & $\begin{array}{l}\text { Aktif } \\
\mathrm{f}(\%)\end{array}$ & $\begin{array}{c}\text { Tidak aktif } \\
\mathrm{f}(\%)\end{array}$ & & \\
\hline $\begin{array}{l}\text { Dukungan Emosional } \\
\text { dan penghargaan }\end{array}$ & & & 0,586 & 1,24 \\
\hline Baik & $44(66,7)$ & $22(33,3)$ & & $(0,569-2,707)$ \\
\hline Kurang & $29(61,7)$ & $18(38,3)$ & & \\
\hline Dukungan instrumental & & & 0,449 & 1,36 \\
\hline Baik & $49(67,1)$ & $24(32,9)$ & & $(0,612-3,027)$ \\
\hline Kurang & $24(60,0)$ & $16(40,0)$ & & \\
\hline $\begin{array}{l}\text { Dukungan } \\
\text { informasional }\end{array}$ & & & 0,194 & 0,57 \\
\hline Baik & $44(60,3)$ & $29(39,7)$ & & $(0,249-1,330)$ \\
\hline Kurang & $29(72,5)$ & $11(27,5)$ & & \\
\hline
\end{tabular}

Tabel 8 menunjukkan bahwa dari responden yang mendapat dukungan emosional dan penghargaan baik, 66,7\% nya aktif dalam kegiatan posyandu lansia, sedangkan dari responden yang dukungan emosional dan penghargaan kurang $61,7 \%$ yang aktif. Namun, hubungan dukungan emosional dan penghargaan tidak berpengaruh secara statistik dengan keaktifan peserta posyandu lansia, dengan nilai $\mathrm{p}>0,05$ $(\mathrm{p}=0,586)$ dan nilai $95 \%$ CI OR mencakup angka 1 (95\%CI OR= 0,569-2,707). Namun demikian nilai OR hubungan dukungan emosional dan penghargaan dengan keaktifan peserta posyandu lansia adalah 1,24, kali lebih aktif dalam mengikuti kegiatan posyandu lansia dibandingkan dengan yang dukungan keluarganya kurang. Untuk dukungan keluarga secara Instrumental responden mendapat dukungan instrumental baik. 67\% nya aktif dalam kegiatan posyandu lansia, sedangkan dari responden yang dukungan instrumental kurang hanya $32,9 \%$ yang aktif. Namun, hubungan dukungan insrumental tidak berpengaruh secara statistik dengan keaktifan peserta posyandu lansia, dengan nilai $\mathrm{p}>0,05$ $(\mathrm{p}=0,449)$ dan nilai $95 \%$ CI OR mencakup angka 1 (95\%CI OR=0,612-3,027). Namun demikian nilai OR hubungan dukungan instrumental dengan keaktifan peserta posyandu lansia adalah 1,36, artinya odd peserta posyandu lansia yang mendapatkan dukungan baik dari keluarganya 1,36 kali lebih aktif dalam mengikuti kegiatan posyandu lansia dibandingkan dengan yang dukungan keluarganya kurang. Untuk dukungan informasional responden mendapat dukungan informasional baik. 60,3\% nya aktif dalam kegiatan posyandu lansia, sedangkan dari responden yang dukungan informasional kurang hanya 39,7\% yang aktif. Namun, hubungan dukungan informasional tidak berpengaruh secara statistik dengan 
keaktifan peserta posyandu lansia, dengan nilai $\mathrm{p}>0,05(\mathrm{p}=0,194)$ dan nilai $95 \% \mathrm{CI}$ OR mencakup angka 1 (95\%CI OR= 0,2491,330). Nilai OR hubungan dukungan informasional dengan keaktifan peserta posyandu lansia adalah 0,57 , artinya odd peserta posyandu lansia yang mendapatkan dukungan baik dari keluarganya 0,57 kali menurun keaktifannya dalam mengikuti kegiatan posyandu lansia dibandingkan dengan yang dukungan keluarganya kurang.

\section{DISKUSI}

Sesuai dengan tujuan penelitian yang ingin mengetahui dukungan keluarga terhadap peserta posyandu lansia di Desa Sudimara dan Desa Gubug tahun 2019, maka akan dilakukan pembahasan hasil penelitian mengenai dukungan keluarga tersebut.

Friedman (2010) mendefinisikan keluarga sebagai suatu system sosial. Keluarga merupakan sebuah kelompok kecil yang terdiri dari individu-individu yang memiliki hubungan erat satu sama lain, saling tergantung yang diorganisir dalam satu unit tunggal dalam rangka mencapai tujuan tertentu. Dukungan keluarga merupakan suatu proses hubungan antara keluarga dengan lingkungan sosial.

Hasil analisa data dari 113 responden menunjukan bahwa nilai tengah variable dukungan keluarga terhadap lansia adalah 35. Berdasarkan aspek dukungan emosional dan penghargaan, sebagian besar responden dalam penelitian ini selalu dimaklumi oleh keluarganya ketika rentan menderita penyakit karena usia lanjut yaitu 61,1\% responden dan hanya $8,8 \%$ responden yang sama sekali tidak pernah didampingi oleh keluarganya saat kegiatan posyandu lansia. Berdasarkan aspek dukungan instrumental, sebagian besar responden dalam penelitian ini selalu dibiayai keperluan untuk mengikuti posyandu lansia oleh keluarganya yaitu 87,6\% responden dan hanya $1,8 \%$ responden yang keluarganya tidak pernah menyediakan waktu dan kendaraan untuk mengantar saat kegiatan posyandu lansia. Sedangkan dari aspek informasional, sebagian besar responden dalam penelitian ini selalu diingatkan oleh keluarganya jika ada hal-hal yang kurang jelas tentang posyandu lansia yaitu 90,3\% responden. Hal tersebut menunjukan bahwa sebagian besar responden mendapat dukungan baik dari keluarganya secara emosional dan penghargaan, instrumental, dan juga dukungan informasional. Terdapat 58 responden $(51,3 \%)$ yang mendapat dukungan keluarga baik. Dari aspek dukungan emosional dan penghargaan 66 responden $(58,4 \%)$ mendapat dukungan baik dan 73 responden $(64,6 \%)$ mendapat dukungan baik dari aspek instrumental. Dukungan informasional yang di dapat responden sebagian besar tergolong baik sebanyak 73 responden $(64,6 \%)$.

\section{SIMPULAN}

Dari uraian diatas, peneliti dapat menyimpulkan sebagai berikut, Hasil analisis menunjukan bahwa responden mendapat dukungan baik dari 
keluarganya secara emosional dan penghargaan, instrumental, dan juga dukungan informasional. Terdapat 58 responden (51,3\%) yang mendapat dukungan keluarga baik. Dari aspek dukungan emosional dan penghargaan terdapat 66 responden $(58,4 \%)$ mendapat dukungan baik dan terdapat 73 responden $(64,6 \%)$ mendapat dukungan baik dari aspek instrumental. Sebagian besar responden mendapat dukungan informasional baik sebanyak 73 responden (64,6\%).

Responden dalam penelitian ini aktif mengikuti kegiatan posyandu lansia yaitu sebanyak 73 responden $(64,6 \%)$ ini masih di bawah target yaitu $80 \%$.

Hubungan dukungan keluarga secara umum tidak berpengaruh secara statistik dengan keaktifan peserta posyandu lansia $(\mathrm{p}=0,319 ; \quad 95 \% \mathrm{CI} \quad \mathrm{OR}=\quad 0,683-3,215 ;$ $\mathrm{OR}=1,48)$.

Pada dukungan emosional dan penghargaan mendapatkan nilai OR yaitu 1,24, artinya responden yang mendapat dukungan emosional dan penghargaan baik 1,24 kali lebih aktif di bandingan dengan responden yang mendapatkan dukungan emosional dan penghargaan yang kurang dari keluarganya.
Pada dukungan instrumental mendapatkan nilai OR yaitu 1,36, artinya responden yang mendapat dukungan instrumental baik 1,36 kali lebih aktif di bandingan dengan responden yang mendapatkan dukungan instrumental keluarganya kurang dari keluarganya.

Pada dukungan informasional mendapatkan nilai OR yaitu 0,57 , artinya responden yang mendapat dukungan informasional baik dari keluarganya 0,57 kali menurun keaktifannya dalam mengikuti kegiatan posyandu lansia dibandingkan dengan responden yang mendapatkan dukungan informasional yang kurang dari keluarganya.

\section{SARAN}

Berdasarkan hasil penelitian maka peneliti ingin memberikan saran antara lain bagi keluarga lansia, disarankan kepada keluarga agar memberikan perhatian khusus dan dukungan kepada lansia mulai dari dukungan emosional dan penghargaan seperti ikut mendampingi setiap kegiatan posyandu lansia, memberikan dukungan emosional seperti menyediakan waktu dan kendaraan untuk mengantar lansia ke posyandu lansia dan memberikan dukungan informasional seperti 
mengingatkan lansia tentang prilakuprilaku yang dapat memperburuk kesehatan lansia. Bagi Petugas Kesehatan, disarankan untuk petugas Kesehatan/Puskesmas dapat lebih meningkatkan pelayanan posyandu lansia dan pendidikan masyarakat/penyuluhan kesehatan tentang manfaat posyandu lansia. Selain penyuluhan, teknik dalam penyampaian informasi salah satunya dengan cara diskusi partisipan. Pemberian informasi tidak hanya searah saja, tetapi dua arah sehingga masyarakat atau lansia dapat berdiskusi tentang apa yang kurang dipahami agar informasi yang disampaikan mudah dipahami dan direspon oleh masyarakat/lansia.

$$
\text { Bagi Peneliti Selanjutnya, }
$$
disarankan kepada penelitian selanjutnya untuk meneliti faktor-faktor lain yang mempengaruhi keaktifan peserta posyandu lansia. Disamping itu, dalam pelaksanaan penelitian dengan populasi lansia sebaiknya menggunakan penelitian kualitatif dan menggunakan metode partisipatif untuk mengurangi bias dalam proses pengumpulan data.

\section{DAFTAR PUSTAKA}

Badan Pusat Statistik. (2014). Statistik Penduduk Lanjut Usia. Jakarta: Badan Pusat Statistik.

Depkes RI. (2000). Kompetensi Bidan Indonesia. Jakarta: IBI.

Dinas Kesehatan Kabupaten Tabanan. (2018). Laporan Tahunan Dinas Kesehatan Kabupaten Tabanan Tahun 2018. Tabanan: Dinas Kesehatan Kabupaten Tabanan.

Dinas Kesehatan Provinsi Bali. (2018). Profil Tahunan Dinas Kesehatan Provinsi Bali Tahun 2018. Bali: Dinas Kesehatan Provinsi Bali.

Friedman, G. (2010). Buku Ajar Keperawatan Keluarga. Jakarta: EGC.

Handayani, D. \& Wahyuni. (2012). Hubungan Dukungan Keluarga Dengannn Kepatuhan Lansia Dalam Mengikuti Posyandu Lansia di Posyandu Jetis Desa Krajan Kecamatan Weru Kabupaten Sukoharjo. GASTER. 9 (1) : 49-58.

Kemenkes RI. (2012). Penyakit Tidak Menular. Buletin dan Jendela Data Kementerian kesehatan RI. Jakarta: Kementerian Kesehatan RI.

Nursalam. (2014). Metodelogi Penelitian Ilmu Keperawatan. Jakarta: Salemba Medika.

Puskesmas Tabanan I. (2018). Laporan Puskesmas Tahun 2017. Tabanan: Puskesmas Tabanan I. 